\title{
A big data analytics architecture for cleaner manufacturing and maintenance processes of complex products
}

\author{
Zhang Yingfeng ${ }^{\text {a, }}{ }^{*}$, Ren Shan ${ }^{\text {a, c }}$, Liu Yang ${ }^{\text {b }}$, Si shubin ${ }^{\text {a }}$ \\ ${ }^{a}$ Key Laboratory of Contemporary Design and Integrated Manufacturing Technology, Ministry of Education, \\ Northwestern Polytechnical University, Shaanxi, P.R.China, 710072 \\ ${ }^{\mathrm{b}}$ Department of Production, University of Vaasa, Vaasa, Finland \\ c Department of Mechanical Engineering, Honghe University, Yunnan, P.R.China, 661199 \\ * Corresponding Author: Zhang Yingfeng (zhangyf@nwpu.edu.cn)
}

\begin{abstract}
Cleaner production (CP) is considered as one of the most important means for manufacturing enterprises to achieve sustainable production and improve their sustainable competitive advantage. However, implementation of the CP strategy was facing barriers, such as the lack of complete data and valuable knowledge that can be employed to provide better support on decision-making of coordination and optimization on the product lifecycle management (PLM) and the whole CP process. Fortunately, with the wide use of smart sensing devices in PLM, a large amount of real-time and multi-source lifecycle big data can now be collected. To make better PLM and CP decisions based on these data, in this paper, an overall architecture of big data-based analytics for product lifecycle (BDA-PL) was proposed. It integrated big data analytics and service-driven patterns that helped to overcome the above-mentioned barriers. Under the architecture, the availability and accessibility of data and knowledge related to the product were achieved. Focusing on manufacturing and maintenance process of the product lifecycle, and the key technologies were developed to implement the big data analytics. The presented architecture was demonstrated by an application scenario, and some observations and findings were discussed in details. The results showed that the proposed architecture benefited customers, manufacturers, environment and even all stages of PLM, and effectively promoted the implementation of CP. In addition, the managerial implications of the proposed architecture for four departments were analyzed and discussed. The new CP strategy provided a theoretical and practical basis for the sustainable development of manufacturing enterprises.
\end{abstract}

Key words: Cleaner production, Product lifecycle, Manufacturing, Maintenance, Big data analytics, Data mining, Sustainable production

\section{Introduction}

The increasing pressure from manufacturing industry on the energy consumption, especially the accompanying pollution threats, calls for a more environmental-friendly production mode. Cleaner production (CP) has been hailed for the several economic, environmental and social benefits it can provide (Silva et al., 2013; Kantola et al., 2015), and is 
considered as one of the most important means for manufacturing enterprises to realize sustainable production.

The United Nations Environmental Program (UNEP) defines CP as the continuous application of an integrated preventive environmental strategy to production, processes and services in order to increase eco-efficiency to reduce risks for humans and the environment (UNEP DTIE, 1996). CP seeks to promote production efficiency, environmental management, and human development. The priority is to eliminate or minimize waste and emissions generated in its sources rather than correct them at the end of the process. It can be summarized from some literatures (USEPA,1998; Kupusovic et al., 2005; Ball et al., 2009; Corominas et al., 2013) that this source reduction can be accomplished through the following measures: (1) improvement of management and operation (scientific management of production and maintenance management); (2) improvement of technology (update of technical and technological process); (3) improvement of product design; (4) improvement of service pattern; (5) cleaner raw material; (6) material recycling.

These measures implied: (1) CP encompasses production processes and management procedures, as well as the organizational dimensions of environmental management, aiming to include the whole life cycle of the product (USEPA, 1998); and (2) CP is applicable not only to productive processes but also to products and services (UNIDO, 2002). Therefore, it can be said that CP presents an integrated and systemic approach as it includes changes in the whole product lifecycle stages related to production, manufacturing, maintenance, service, and recycling. Its definition reflects a search for continuous improvement, which is also an important principle to achieve the goal of product lifecycle management (PLM). As pointed out by Giannetti et al. (2008), sometimes few changes (during lifecycle stages) can make obvious differences to the economy and the environment in CP practice. In general, product lifecycle consists of three phases: beginning of life (BOL), including design and manufacturing; middle of life (MOL), including use, service and maintenance; and end of life (EOL) including remanufacturing, recycling, reuse and disposing (Jun et al., 2007; Jun et al., 2009).

So far, CP and PLM have become effective strategies for enterprises to improve their sustainable competitive advantage (SCA) with the development of an enterprise informationalization. Liu (2013) develops a theoretical model to explore the core factors which determine SCA of firms. Liu and Liang (2015) put forward the alignment of operating strategy with resource allocation, and reveal the optimal adjustments of resource-based strategy for lifecycle by analyzing the original data of 18 companies which can lead to SCA.

Despite the potential economic and environmental benefits CP strategy can provide, the implementation of CP program continues facing problems and barriers, for instance, insufficient supply of equipment and information, lack of information about clean technologies, available procedures, and organizational capabilities, as well as poor communication systems (MurilloLuna et al., 2011); managerial and organizational barriers include behavioral barriers, 
such as resistance to change, lack of willingness to embrace new technologies and procedures (Callia et al., 2009; Stone, 2000); insufficient awareness and knowledge of CP as well as many cleaner technologies internationally available, lack of skills (Luken and Rompaey, 2008; Zhang et al., 2015; Zhang et al., 2016); barriers to availability and accessibility for the information or knowledge relevant to a product (Cheung et al., 2015; Candido et al., 2011).

These above problems are mainly due to the is lack of detailed and real-time lifecycle data and valuable knowledge that can be employed to achieve desired results in each lifecycle stage, which could ultimately hinder the whole CP and PLM process. In other words, the key problems are how to capture lifecycle data, how to discover knowledge from the data, and how to share knowledge among all lifecycle stakeholders so that CP strategy can be successfully implemented.

In light of the questions above, this paper proposes a new CP method enhanced by a systematic integration of PLM and big data analytics that helps to overcome the aforementioned problems. Here we are concerning on big data-based manufacturing applications specifically in manufacturing and maintenance process (MMP) of product lifecycle. Here, the manufacturing process includes Research \& Development and Manufacture (RDM), and the maintenance process includes Operation and Maintenance (OM). The focus is placed upon developing system architecture of big data analytics, discussing key technologies and analyzing how to use the architecture to share information and knowledge among all lifecycle stakeholders. The following research questions are of our particular interest.

- How to establish an overall architecture of big data-based analytics for product lifecycle (BDA-PL), and to provide enterprises with an integrated and systemic approach to implement a CP program?

- How to establish an overall data acquisition and integration framework for MMP to sense and exchange multi-source heterogeneous big data during whole lifecycle, and to solve the problem of lacking of data in the process of CP implementation?

- How to excavate and discover valuable knowledge from MMP big data to overcome the shortage of knowledge during the implementation of CP?

By addressing these questions, the rest of the paper is structured as follows. A comprehensive literature review was conducted in Section 2. Then an overall architecture of BDA-PL was built in Section 3, followed by the development of the key technologies related to big data analytics in Section 4. Section 5 illustrated an application scenario that how the proposed architecture can be applied to an axis compressor manufacturer. Finally, discussions and conclusions were given in Section 6 and Section 7, respectively.

\section{Literature review}

Two streams of literature are relevant to this research. These include (1) Internet of Things (IoT) technology and its 
application in PLM, and (2) big data and data mining technology application in manufacturing.

\subsection{IoT technology and its application in PLM}

Thanks to the emerging advanced technologies related to product identification, wireless sensors, Radio Frequency Identification (RFID), communication technologies, especially information network technologies have created a new era of the Internet of Things (IoT) (Zhang et al., 2014). IoT provides an IT-infrastructure to facilitate the information exchange of "things and processes" in a real-time and reliable manner. Therefore, more and more manufacturing enterprises begin to implement the IoT technology (e.g. RFID) to manage their business (e.g. manufacturing execution system (MES), shop-floor dynamic scheduling, etc.). Consequently, lifecycle actors can now obtain data through the whole product lifecycle. These technologies can also bring new opportunities for CP and PLM. As is pointed out by Kiritsis et al. (2003), RFID technology can bring opportunities to access, manage, and control product data and information over the whole product lifecycle.

Some scholars have explored the practice of IoT technologies in PLM. To investigate what are the main components for closed-loop PLM and how they are related to each other, Jun et al. (2007) proposed the system architecture for closed-loop PLM which includes business, hardware, and software model. Jun et al. (2009) introduced an overall framework for RFID applications in PLM. Some examples of potential and real applications are introduced. Lee et al. (2009) presented a new paradigm for design and manufacturing via ubiquitous technology which was called ubiquitous product lifecycle support (UPLS) system. Georgiadis and Athanasiou (2010) studied predictive maintenance and remanufacturing application based on closed-loop PLM. Based on RFID technology, Wang et al. (2010) proposed a digital warehouse management system in the tobacco industry. By using RFID technology, the system enabled a plane warehouse to achieve visualized inventory management, automatic storage assignment and high accuracy of inventory control. Combining RFID technology with ontologies, Grüninger et al. (2010) created smart objects in the context of manufacturing process to solve the problem of massive RFID tags interoperability. Xu et al. (2009) focused on the closed-loop product information tracking and feedback in a wireless technology enabled environment from the point of view of modelling. Zhang et al. (2015a) studied the real-time information-driven control and optimization method of the assembly process in a synchronous line. Extensive references can be found in the literatures (Yang et al., 2009; Sallez et al., 2010; Osman et al., 2010; Hadaya and Marchildon, 2012; Zhang et al., 2015b). From this review, although significant progress has been made in the above researches, there are some challenges and limitations in applying the real-time data-driven PLM.

- The researches above mainly focus on how to apply the IoT related techniques on one stage of PLM (such as 
manufacturing process of BOL), and the overall solution for the whole lifecycle is seldom investigated.

- There is lack of systematic solution of automatic identification and capturing for lifecycle data, which may lead to two problems: (1) during the manufacturing and maintenance process, data acquisition is inaccurate and incomplete; (2) the research and development (R\&D) cycle of product is prolonged, and maintenance time is increased. These problems hinder the decision-making of whole lifecycle, and ultimately affect the implementation efficiency of CP.

\subsection{Big data and data mining technology application in manufacturing}

Nowadays, the most famous characteristics of big data have been concluded as 3Vs theory: volume, variety, and velocity (Laney, 2001). As manufacturing enterprises begin to widely use advanced information technology to carry out their general management, a large amount of data related to product lifecycle are produced. According to the 3Vs theory, in the field of MMP, big data refers to a large amount of multi-source, heterogeneous and real-time data, which is generated during R\&D, manufacture, operation, and maintenance stages (e.g. design information, materials list, assemble instruction, production history data, production plan, inventory status, quality information of each component, operational conditions, operating time, failure causes, maintenance history, etc.). These data is characterized by 3Vs theory, and increasing at the exponential speed. The era of industrial big data has come. To reveal invaluable new insight and knowledge from the data, the big data analytics has been causing extensive concerns in the finance, manufacturing, medical treatment and even government, due to its advantage on the intelligent applications and extraordinary capabilities to integrate, process, and analyze the dynamic and real-time data.

In terms of manufacturing, the big data analytics will make a significant impact on $\mathrm{R} \& \mathrm{D}$, manufacture, customer service, maintenance/repair and overhaul (MRO) technical support, recycling and remanufacturing. It can also effectively promote the implementation of $\mathrm{CP}$, as well as the development of sustainable production and consumption. When considering all aspects of product lifecycle, the solution to the implementation of big data is still a challenge to manufacturing enterprises. Galletti and Papadimitriou (2013) investigated how big data analytics can be perceived and used as a driver for enterprises' competitive advantage. Big data implemented in cloud was introduced for developing an easy and highly scalable application for dataflow-based performance analysis (Dai et al., 2011). A comprehensive investigation of big data challenges for enterprise application performance management was discussed so that the big data application in industry could be promoted based on the lessons learned from this investigation (Rabl et al., 2012). Auschitzky et al. (2014) introduced an in-depth analysis of the issues on how to utilize big data mining and advanced analytics to make manufacturing decisions more rational. Through the analysis of several cases by Auschitzky, the methods of how big data provide assistance for business decisions were illustrated. Li et al. (2015) investigated the 
concept, characteristics, and potential applications of big data in PLM. At the same time, the various data involved in the three main phases of PLM are concluded and analyzed.

In modern manufacturing environments, vast amounts of data are collected in database management systems from the whole product lifecycle. Data mining has emerged as an important tool for knowledge acquisition from manufacturing databases. By constructing a decision tree, Metan et al. (2010) proposed a new scheduling system for selecting dispatching rules in real-time. The proposed scheduling system was developed by combining the techniques of simulation, data mining, and statistical process control charts. For evaluating the agility in supply chains, Vinodh et al. (2011) reported the utilization of fuzzy association rules mining approach which enabled the decision makers to make flexible decisions in the presence of attributes such as flexibility, quality, innovativeness, pro-activity and cost. Bayesian algorithm is used to discover priority dispatching rules from large amounts of structured or unstructured data for the single machine scheduling problem (Premalatha and Baskar, 2012). Chen et al. (2012) proposed an integrated model by combining K-means clustering, feature selection, and the decision tree method into a single evaluation model to address evaluation problem of suppliers in the supply chain. Bennane and Yacout (2012) investigated the application of a data mining technique called logical analysis of data to condition-based maintenance. Magro and Pinceti (2009) presented a technique to improve the accuracy of predictions using the rough set theory in non-deterministic cases. Mavridouet al. (2013) established a model applied neural network algorithm to identify bearing faults in wind turbines. Purarjomandlangrudi et al. (2014) presented a data mining approach called anomaly detection to discriminate defect examples of rolling-element bearing failures. Extensive references can be found in the literature (Choudhary et al., 2009; Ngaiet al., 2009; Köksal et al., 2011; Jeong and Shimoyama, 2011; Kusiak and Verma, 2012; Geng et al., 2012; Chien et al., 2013; Mavridou et al., 2013; Lee et al., 2014). From this review, several observations can be made about the current situation of data mining applications in manufacturing.

- Most data mining applications only focus on the single stage of the lifecycle, such as shopfloor scheduling of manufacture, and fault diagnosis of OM. Little effort has been devoted to the investigation on excavating the valuable knowledge from the integrated data of all stages of MMP.

- Little effort has been devoted to the integrated application of knowledge obtained by data mining in each stage of MMP. The results of data mining cannot be effectively integrated, so that they cannot provide better support for decision-making of the optimization on PLM, nor successfully implement of CP.

\section{An overall architecture of BDA-PL}

By applying IoT technology to each stage of the lifecycle, a smart manufacturing and maintenance environment is 
established, and the multi-source heterogeneous big data of lifecycle can be captured. Then there is a need of theories and methods of big data analytics to find hidden patterns and associated relationships from lifecycle data. Based on the integrated application of big data mining results, better decision-support for innovation design, management and operation improvement, and technology and service patterns improvement are provided to enterprise managers. Finally, the accuracy and effectiveness of PLM decision-making can be improved, and the capability of implementing CP can be enhanced.

Integrated solutions of service-driven pattern and big data-based pattern, active perception of manufacturing resources, real-time monitoring of product status, value discovery of multi-source heterogeneous data, and dynamic optimization of PLM are the significant characteristics of the architecture for BDA-PL.

For the service-driven pattern, the ownership of the product is retained by manufacturing enterprise and the customer purchases use of the product over a given period (or the customer pay for the function or service of the product). Manufacturing enterprise of the product sells its function or service instead of product through sharing or leasing mode. Consequently, it is possible to provide its customers with complete solutions (e.g. complete set of engineering project solutions and complicated project management solutions) and systematic service (e.g. specialized maintenance service and remote on-line diagnoses service) due to the rich experiences and specialized knowledge. For the big data-based pattern, a large amount of multi-source, heterogeneous and real-time data of MMP can be gathered through various sensing devices. Then, the data can be used by manufacturing enterprise for big data analysis (e.g. association analysis, prediction analysis, clustering analysis, etc.) and knowledge discovery, which can help decision-makers to obtain new insight and provide optimized decision-making support for MMP. The process of data gathering and data analyzing can easily be carried out by the service-driven mode due to the advanced technology and specialized knowledge of the manufacturing enterprise.

To sum up, the service-driven mode has enabled the manufacturer to monitor and collect the production data and the operation status data of the products. These data can then be used for big data analyses and knowledge discovery. Besides, the big data-based mode can provide reliable and complete data support to the data mining process, and the achieved knowledge and rules can provide the valuable knowledge foundation for manufacturing enterprises to optimize their production process and service strategy.

Based on the ideas above, an overall architecture of BDA-PL is proposed in Fig. 1.

\subsection{Application services of PLM}

For this layer, the objectives of PLM are put forward by manufacturing enterprises (e.g. design improvement, proactive 
maintenance, energy conservation and environment protection, etc.). In general, PLM and CP emphasize on maximizing the coordination between enterprises benefits (including high profits, product design improvement, and predictive maintenance and EOL decision) and environmental benefits (including high energy efficiency and high environment efficiency). According to this goal, a sustainable development paradigm is established. Six types of services (as shown in the right-hand side of Fig. 1) are designed in the architecture. Real-time data and information of product lifecycle can provide important information for the implementation of these services.

\subsection{Big data acquisition and integration}

Based on the configuration of smart devices (e.g.e RFID tags and smart sensors) in manufacturing resources (e.g. machine tool, operators, etc.) and product, the accurate and complete multi-source heterogeneous big data can be captured and transmitted during the whole lifecycle. Integrating data mining result with other enterprise information systems (EISs) (see the lower-right part of Fig. 1) is designed to establish a bridge for processing and exchanging the information between heterogeneous management systems. The business-to-manufacturing markup language (B2MML) and extensible markup language (XML) are adopted to provide standard data schemas for various lifecycle stages, departments and EISs.

\subsection{Big data processing and storage}

Product lifecycle data consists of structured, semi-structured and unstructured data. Storm (http://storm.apache.org/) real-time computing framework is used to process the data (e.g. condition monitoring data) which need a high real-time processing ability. However, a large number of non-real-time data is stored to provide reliable and complete raw data support on further data analysis. Hadoop (http:/hadoop.apache.org/; Wei, 2013) computing framework is used to process the non-real-time data. Distributed database system (DDBS), Hadoop distributed file system (HDFS) (White, 2012) and structured query language (SQL) data management system are used to store the heterogeneous big data.

\subsection{Big data mining and knowledge discovery in database (KDD)}

By using the theories and methods of big data analytics and data mining, valuable information and knowledge can be discovered from the big data of product lifecycle. By integrating big data mining result with product data \& knowledge management (PDKM) system and decision support system (DSS), a closed-loop mechanism of knowledge share and feedback is formed among all lifecycle stages. Lifecycle optimization and CP for manufacturing enterprise can be achieved only when the knowledge sharing is realized in all individual phases of the product lifecycle. The clustering, prediction, regression, classification, and association analysis models are established to obtain the knowledge from data. 


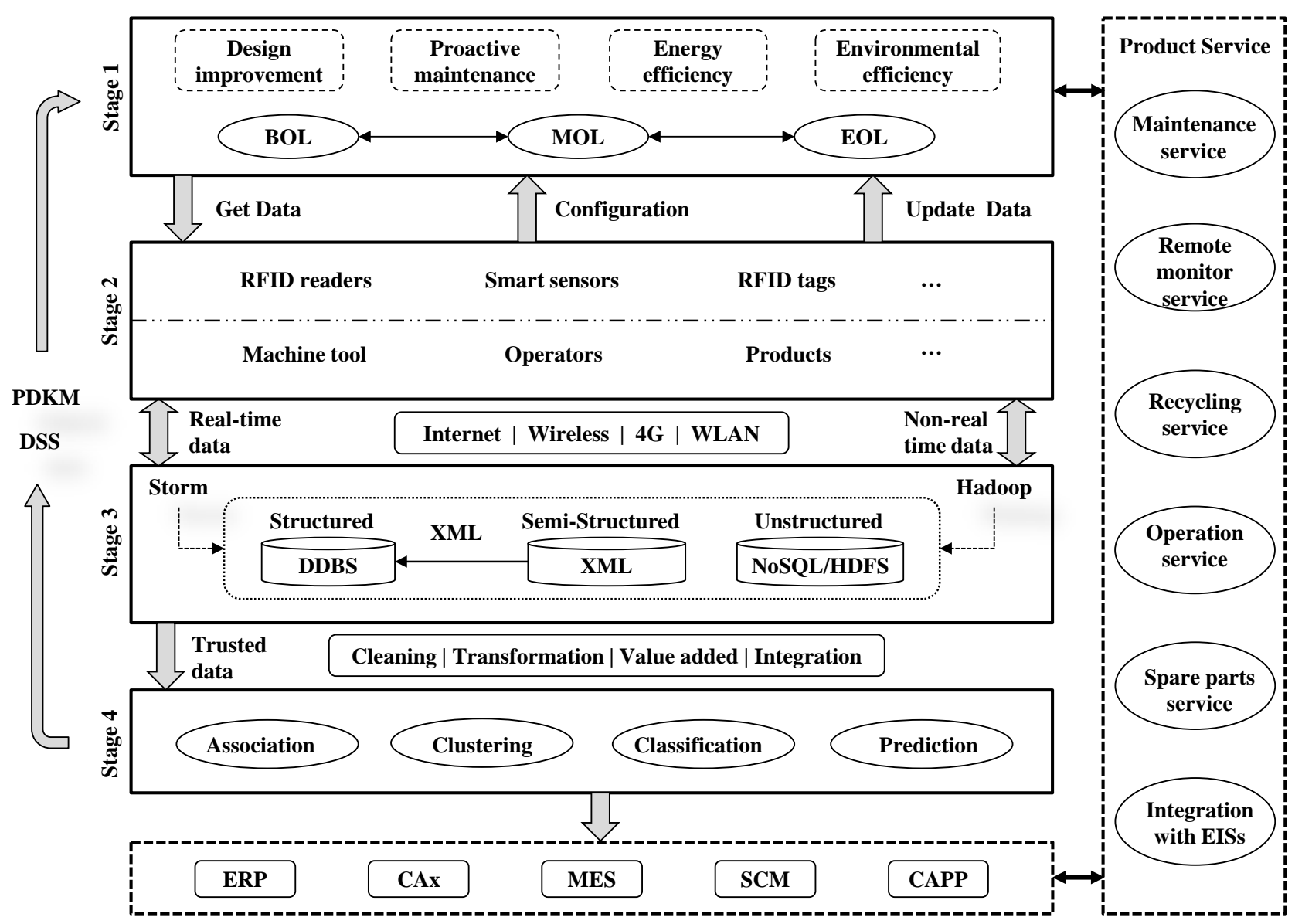

Stage 1: Application services of product lifecycle management Stage 3: Big data processing and storage

Stage 2: Big data acquisition and integration

Stage 4: Big data mining and knowledge discovery in database

Fig. 1. Overall architecture of big data-based analytics for product lifecycle.

\section{Key technologies of big data-based analytics for MMP}

MMP big data plays an important role in PLM. For manufacturing enterprises, it is a significant knowledge asset of CP, product innovation, and proactive maintenance; for EOL decision-making, it can minimize waste and landfill, and ensure that the product can be reused and remanufactured. However, it is difficult to capture the real-time and complete MMP data, especially the data of the products after being delivered to customers, without temporal and spatial constraints.

In order to solve the problems above, in this section, an overall framework for real-time and multi-source heterogeneous big data acquisition and integration of MMP is designed. Then a graphical model of big data mining is put forward to carry out MMP big data mining, and the knowledge sharing mechanism of MMP is also discussed. This paper mainly illustrates the ideas and methods of the key technologies.

\subsection{MMP big data acquisition and integration}

An overall framework for real-time and multi-source big data acquisition and integration of MMP is designed in Fig. 2. 
The configuration of the various smart devices and product embedded information devices (PEIDs) (e.g. RFID tags, sensors) for manufacturing things and product are the foundations of multi-source heterogeneous big data capturing.

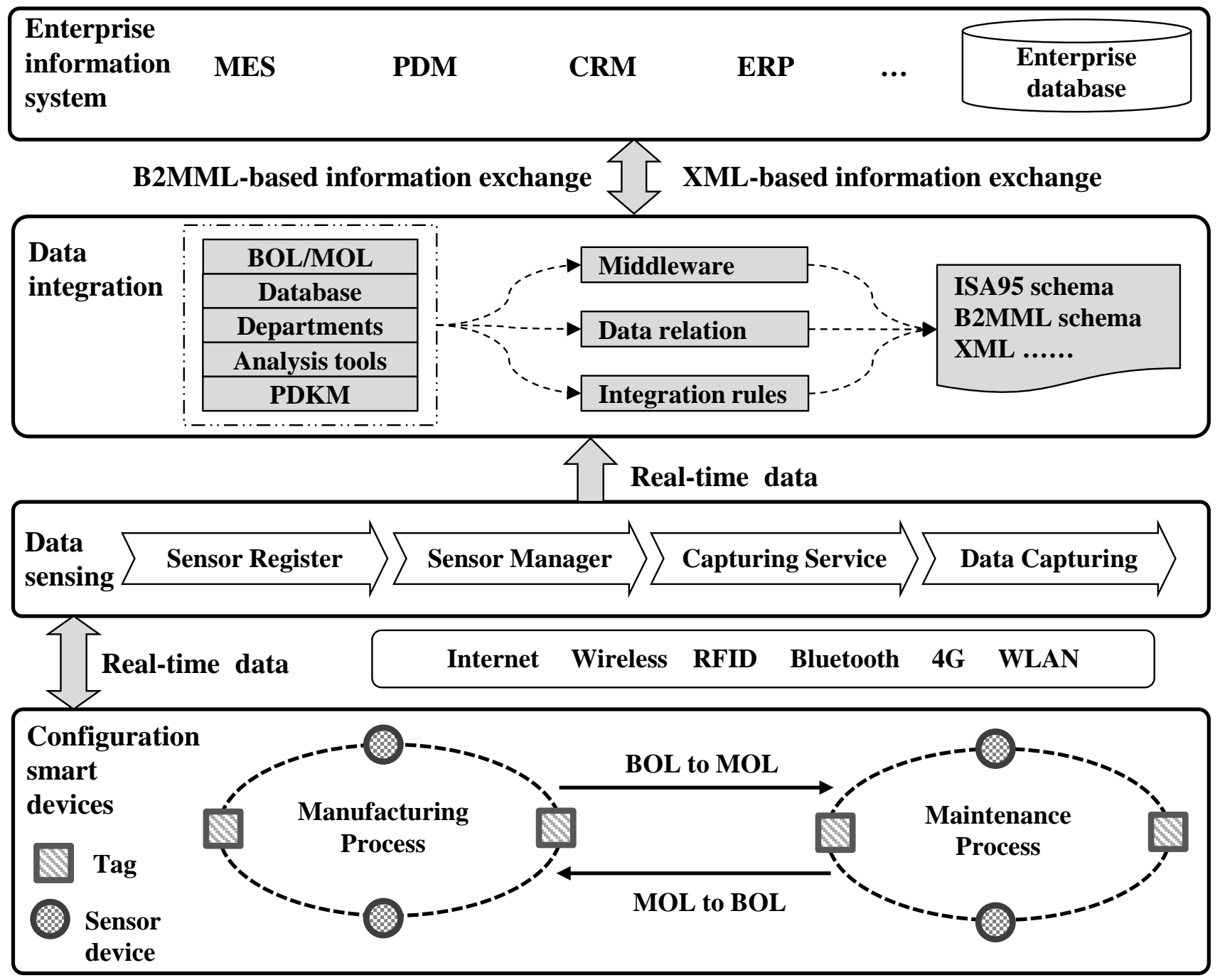

Fig. 2. Overall framework of big data acquisition and integration for the manufacturing and maintenance process.

During the manufacturing phase, PEIDs are deployed to manufacturing resources and key parts of the products. For example, RFID readers are installed in the fixed manufacturing resources such as the CNC center, the entrance to the workshop inventory and key equipment of the assembly line. Operators, loading containers, key parts and suitable position of the products are equipped with RFID tags or sensors.

Based on the configuration of PEIDs, sensors which are equipped in the manufacturing resources and products are able to sense and capture the real-time primitive events. For instance, during the production phase, when the manufacturing resources that embedded the PEIDs come to a sensing area, the primitive event is sensed by the registered sensors (shown in Fig. 1). Through the communication protocol in the registry, the sensors can capture the data of the coming manufacturing resources and transmit the data to enterprise database. During operation stage, these PEIDs can be used to 
monitor and capture real-time operation status data of products.

A huge amount of data captured at the PEIDs cannot be directly used in the upper-level EISs. Therefore, all data generated by various lifecycle phases, departments and software have to be integrated to ensure the data can be shared correctly among different business segments. By means of the definition of multi-source data relation, establishment of information integration rules and middleware technology, the multi-source heterogeneous sensors data, and sectors data are converted into standard schemas (e.g. ISA95/B2MML/XML). On one hand, these standard formats can be used by PLM decision-making to achieve multi-source data value adding. On the other hand, they can be directly used by EISs. From decisions to operations, it can receive enterprise’s decisions, such as production planning and maintenance service, and translate them into production orders or tasks that can be readily used by shop-floor operators or service departments.

\subsection{MMP big data mining and knowledge sharing mechanism}

\subsubsection{Graphical model of MMP big data mining}

The model of MMP big data mining consists of data layer, method layer, result layer and application layer, as shown in Fig. 3.

Data layer is used to store the big data of MMP, such as product design data, bill of material (BOM) data, assembly data, logistics data, maintenance history and operation status data, etc. According to different application demands, these data are stored in different types of enterprise databases.

Method layer mainly refers to data mining model, including decision tree, rough set theory, support vector machine (SVM), random forest and Apriori, etc. These models are responsible for extracting suitable original data from data layer and discovering knowledge from them.

Result layer is a set of data mining result and knowledge. According to different application demands, suitable data mining model and original data are selected to carry out the data mining. Finally, the knowledge set of various decision-makers, lifecycle stages and application indexes are achieved.

The application layer is also known as a demand layer, which applies valuable knowledge of the result layer to achieve the requirements of enterprises. In this research, some enterprise applications such as product innovation design, job shop dynamic scheduling, predictive maintenance and service improvement, etc. are included.

The analysis above shows that the big data mining graphical model is a close-loop structure that it starts from application demands, and ultimately meets the application demands. Firstly, application demands are proposed. Secondly, according to different indexes and demands, various mining models are established and selected. Thirdly, suitable data is extracted to implement data mining. Finally, knowledge and information are achieved to meet the application demands of 
enterprises.

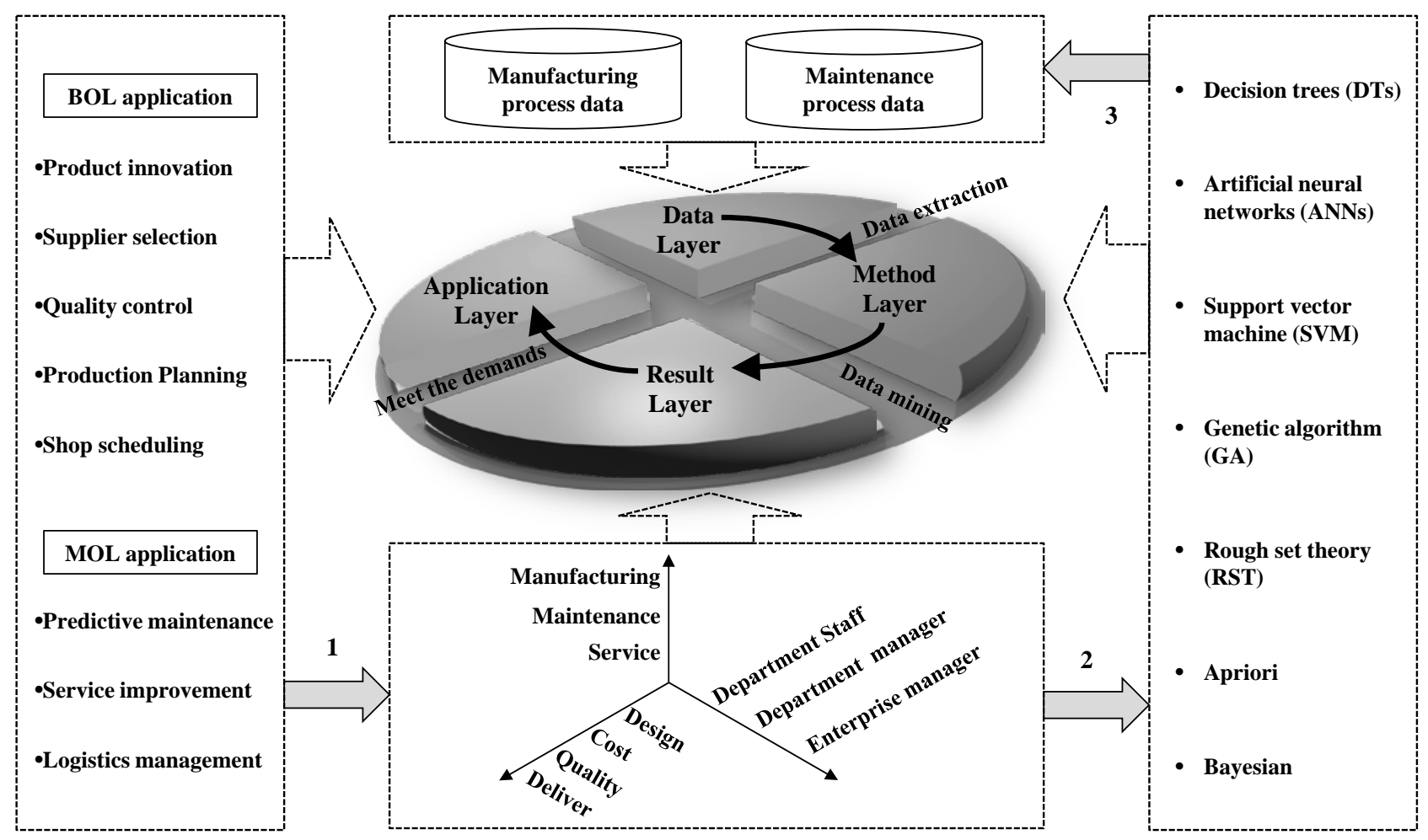

Fig. 3. Graphical model of big data mining for the manufacturing and maintenance process. 1 -put forward application demands; 2 -choose method/model; 3 - extract data.

\subsubsection{MMP knowledge sharing mechanism}

Fig. 4 shows the knowledge sharing mechanism of MMP. Forward and backward knowledge flows are included.

The forward knowledge flows are from BOL to MOL: BOM data, production data, system configuration data, and maintenance instruction of BOL phase are gathered. Using the data mining models (e.g. association analysis model, classification model, prediction model, etc.) embedded in PDKM and DSS, the knowledge is discovered from this data. Then, by PDKM, the knowledge is transmitted to MOL phase. During MOL phase, logistics engineers can use the knowledge to optimize logistics of a product, and maintenance engineers can use them to conduct predictive maintenance or optimize the maintenance process.

The backward knowledge flows are from MOL to BOL: operation data, maintenance history data, failure data and operation environment data of MOL phase are collected during OM process. Then, the hidden knowledge and insight are discovered by data mining models and big data analytics, and the PDKM can feedback the knowledge to BOL phase. Designers and production engineers of BOL phase can exploit the knowledge to improve management, update product design, improve technology and product service patterns, and optimize production plan at BOL. As previously mentioned, CP for manufacturing enterprise can only be achieved when the knowledge sharing is realized in all individual phase of 
the product lifecycle. Therefore, all the changes and improvements above can be achieved by knowledge sharing and feedback of the MMP, and it can ensure the successful implementation of CP program.

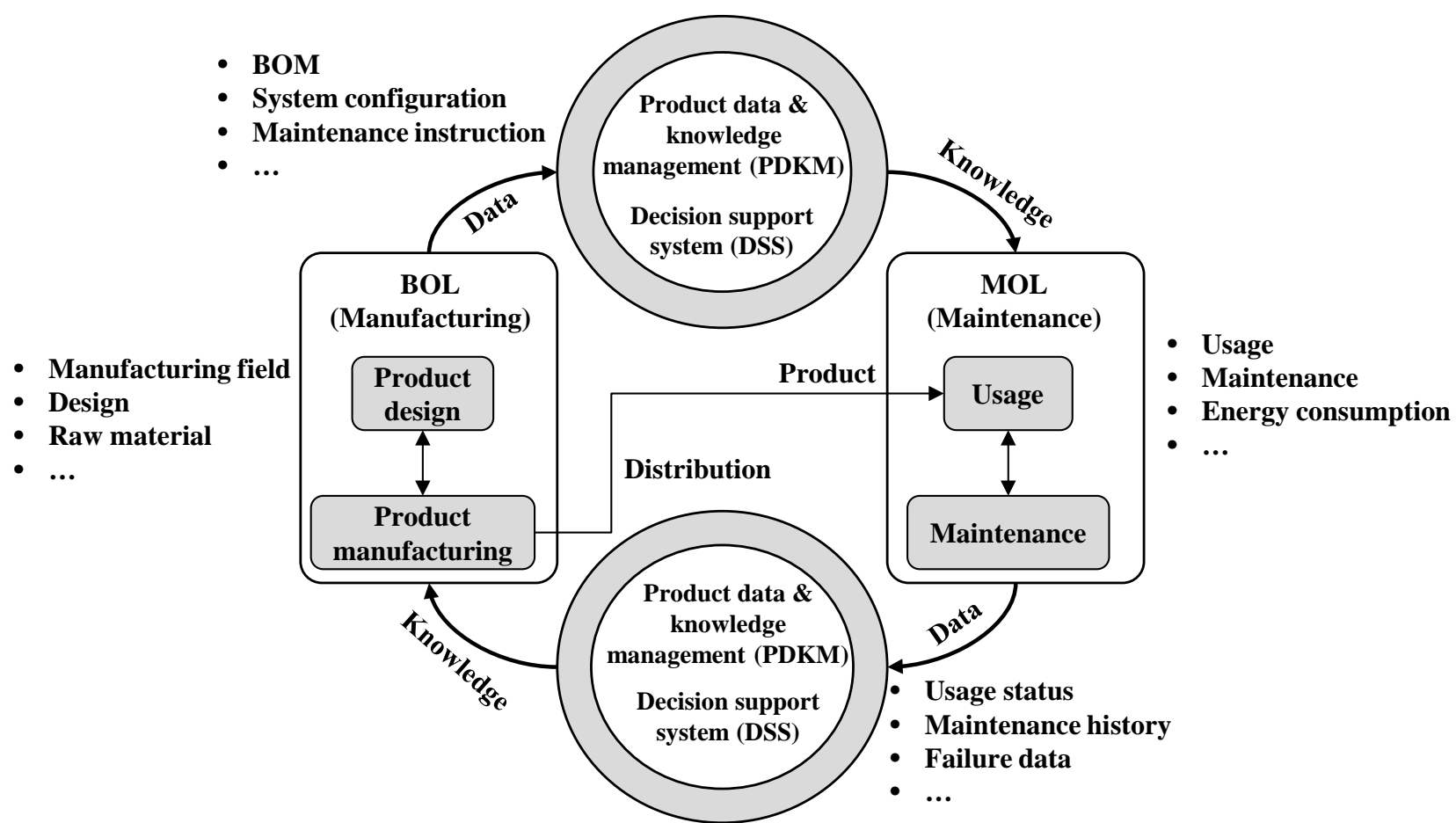

Fig. 4. Knowledge sharing mechanism of the manufacturing and maintenance process.

The knowledge flows not only exist between BOL and MOL, but also exist in their own interiors. As shown in the left-hand side of Fig.4, during BOL phase, the knowledge of manufacturing, design and raw material are exchanged or updated between the manufacturing stage and design stage. By using the knowledge from the manufacturing phase of BOL, the new production process can be adaptively optimized in the design phase of BOL. New material recycling strategy and cleaner raw material can be selected and designed. Meanwhile, during MOL phase (as seen in the right-hand side of Fig.4), operation, maintenance and energy consumption knowledge are shared and exchanged among actors of MOL. With the shared knowledge, design for maintenance and predictive maintenance can be successfully achieved. The knowledge of energy consumption collected and discovered during MOL phase can be used to design for environment and implement the CP strategy.

\section{A study of application scenario}

This section demonstrates the usage of the proposed architecture with an example application of an actual product. Fig. 5 is a schematic diagram of axial compressor manufactured by company $\mathrm{X}$. The axial compressor is mainly composed of the following parts: rotating blade, static blade, adjust cylinder, static blade cylinder, rotor, bearing box, etc. This kind of axial compressor can produce a continuous flow of compressed gas, and have the benefits of high efficiency and 
large mass flow rate. Therefore, it is integral to the design of large gas turbine such as jet engine, high-speed ship engine, and small-scale power station. It is also used in industrial applications such as large-volume air separation plant, blast furnace air, etc. The product is particularly suitable in the application scenario due to its high complexity of structure, and the requirements of high performance and high reliability during its lifetime.

Company $\mathrm{X}$ is specialized in manufacturing axial compressors and turbo-machineries. In the past, just like other manufacturing firms in China, the company only provides pure products to its customers. In order to jump out of this traditional business model, the company decided to transform its manufacturing mode from the product-driven pattern to the system-integration and the service-driven one (Gao et al., 2009; Beuren et al., 2013).

Here we focus on the MMP for the critical components, the rotors and blades of the axial compressors. Due to the influence of pressure and temperature, the flow at the entrance of compressors fluctuates greatly, and would easily cause the axial compressors to go into surging zone. When a surge occurs, the signals such as flow, pressure and temperature, which symbolize the surge, will exhibit the phenomena that are impossible under normal conditions. These abnormal events can be reflected through the real-time operation status data of rotors or blades (e.g. temperature of blades, the vibration of rotors). In the past, the decisions (such as design updating, production optimization, technology improvement, maintenance and material recycling) of compressors lifecycle process were made according to the experience of engineers or some superficial information such as how long the compressors have been used. Different from the previous solution, the proposed decision-making process depends on the results of big data analytics and knowledge discovery from actual MMP big data of compressors rather than only the time of the compressors being used.

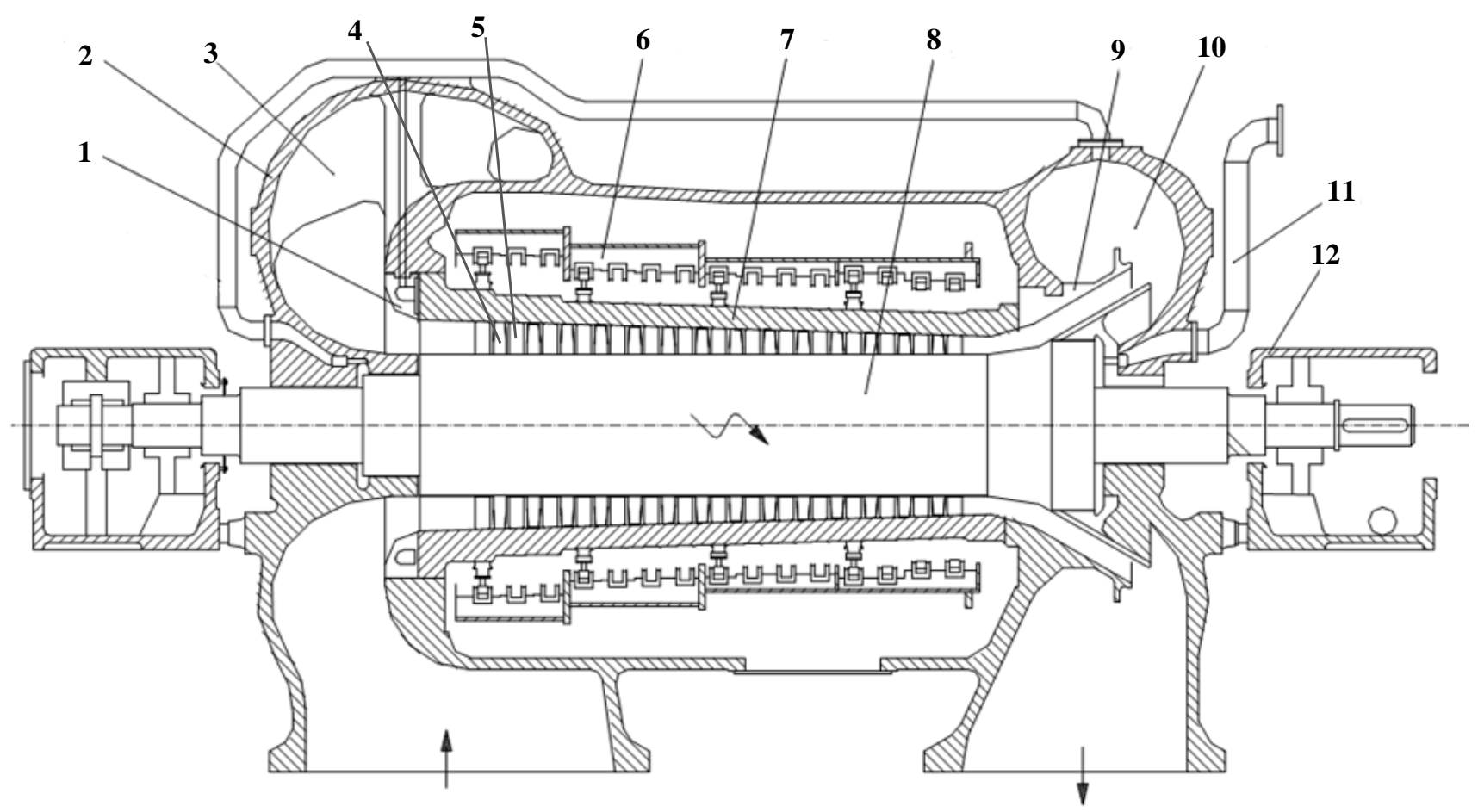


Fig. 5. Schematic diagram of an axial compressor.1 -convergence device; 2 - casing; 3-inlet volute chamber; 4 -rotating blade; 5 -static blade; 6 -adjust cylinder; 7-static blade cylinder; 8 - rotor; 9 - diffuser; 10 -exhaust volute chamber; 11 -exhaust pipe; 12 -bearing box.

Extended source from http://www.china-ogpe.com/buyingguide_content/axial_flow_compressor_1613.html

\subsection{Axial compressor MMP big data acquisition}

This section describes a proof-of-concept application scenario to demonstrate how to implement the BDA-PL architecture. The architecture aims to guarantee the availability and accessibility of the data relevant to manufacturing resources and products. With these data, engineers of BOL are able to analyze the MOL/EOL options, and to eliminate waste or to minimize the consumption in its sources. The study is based on a simplified motivating scenario as shown in Fig. 6.

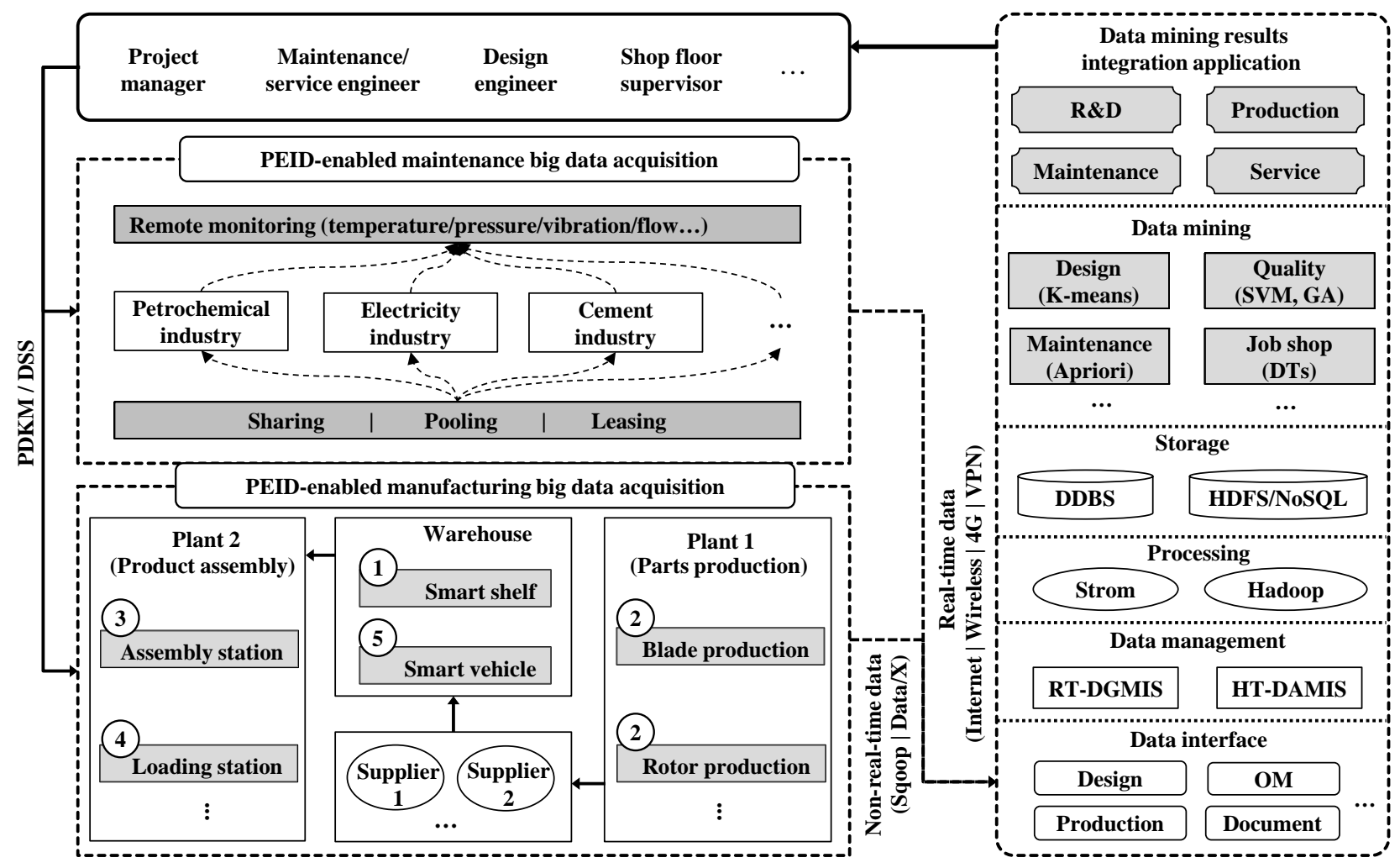

Fig. 6. Overview of the motivating application scenario

\subsubsection{Create a smart environment for MMP with PEID-enabled smart objects}

For the simplicity of understanding but without losing generality of the principle, a hypothetical MMP for the compressors is designed as shown in the left-hand side of Fig. 6. The manufacturing process consists of two plants and one warehouse. In addition, the compressors are leased to petrochemical industry, electricity industry and cement industry, etc. In order to capture the big data of compressors MMP, some smart devices are selected to configure a smart environment of MMP. In this research, UHF RFID, RFID tags, and smart sensors are adopted to track the real-time data. The deployment information is shown in Table 1. 
Table 1

Deployment information of PEIDs in manufacturing shopfloor and product

\begin{tabular}{|c|c|c|c|}
\hline PEIDs & $\begin{array}{l}\text { UHF/ } \\
\text { Sensor Type }\end{array}$ & $\begin{array}{l}\text { Manufacturing } \\
\text { resources/ Location }\end{array}$ & Objective \\
\hline RFID reader & UHF & Machine & Track the pallets, the critical component. \\
\hline RFID reader & UHF & Warehouse gate & Locate the pallet to be delivered, check out the pallet. \\
\hline RFID reader & UHF & Assembly line & $\begin{array}{l}\text { Check in materials delivered from warehouses, check in } \\
\text { WIP and report finished assembly tasks. }\end{array}$ \\
\hline Tag & UHF & Pallet & $\begin{array}{l}\text { Used by a pallet. The real-time information of each pallet } \\
\text { with materials can be tracked. }\end{array}$ \\
\hline Tag & UHF & Each position of the shelf & $\begin{array}{l}\text { The real-time materials information of each position of the } \\
\text { shelf can be tracked. }\end{array}$ \\
\hline Tag & UHF & Critical component & $\begin{array}{l}\text { Attached to the critical component of a product to track the } \\
\text { real-time data from WIP to a product. }\end{array}$ \\
\hline Sensor & $\begin{array}{l}\text { Differential } \\
\text { pressure sensors }\end{array}$ & Convergence device & Monitoring flow rate data of gas. \\
\hline Sensor & $\begin{array}{l}\text { Dynamic } \\
\text { pressure sensors }\end{array}$ & $\begin{array}{l}\text { Inlet and exhaust volute } \\
\text { chamber }\end{array}$ & Monitoring dynamic pressure data of gas. \\
\hline Sensor & $\begin{array}{l}\text { Piezoelectric } \\
\text { velocity sensors }\end{array}$ & Both ends of rolling bearing & $\begin{array}{l}\text { Measuring the axial displacement of rolling bearing to } \\
\text { monitor the vibration characteristics of the rotor. }\end{array}$ \\
\hline Sensor & $\begin{array}{l}\text { Temperature } \\
\text { sensors }\end{array}$ & Embedded in blades and rotor & Monitoring temperature data of gas. \\
\hline
\end{tabular}

The warehouse consists of smart shelves, each of that is equipped with PEIDs (collectively as 1 in Fig. 6). Locations on the shelves are marked. Containers or pallets of materials are also marked. Materials and key components are moved among two plants and warehouse using smart vehicles (marked as 5 in Fig. 6).

Plant 1 is a parts production plant. Some parts of the compressors (e.g. rotors, blades, and cylinders) are manufactured in this plant and are delivered to the warehouse. Company $\mathrm{X}$ has established the strategic cooperation relationships with specialized enterprises. Through such collaboration it can outsource its businesses which are not its own core businesses. These components can also be supplied by the strategic suppliers used for final assembly. The PEIDs (collectively as 2) are configured during the production process. For example, UHF RFID tags are attached on the blades and rotors to track the real-time data from work in process (WIP) to the product. Meanwhile, smart sensors (e.g. temperature sensor and pressure sensor) are embedded in blades and rotors or configured in the proper locations of the compressors to monitor and collect the real-time field data of OM process of compressors. To procure the required real-time field data, the PEID readers (e.g. UHF RFID readers) are also allocated to the appropriate position (e.g. warehouse, machine and assembly line) near the location of the compressors and their components (e.g. within the reading range of PEID readers). 
Plant 2 is assumed to be a simplified axial compressors assembly line. Two work stations are involved. Assembly station is for putting several parts together. The loading station is for export delivery. Each workstation is equipped with various PEIDs. Accordingly, two PEIDs (marked as 3-4) are deployed to these two workstations. Same as Plant 1, some additional sensors should be configured in the proper locations of the compressors during the assembling process. For instance, the differential pressure sensors can be equipped on the convergence device of the compressors to monitor and collect the real-time flow rate data. Dynamic pressure sensors can be equipped on the inlet/exhaust volute chamber to monitor and collect the dynamic pressure data of the air flow. Piezoelectric velocity sensors can be equipped on both ends of rolling bearing, through measuring the axial displacement of rolling bearing to monitor the vibration characteristics of the rotors.

\subsubsection{Real-time acquisition of MMP big data}

Based on the configuration of the smart environment for MMP, the real-time data of the PEIDs equipped to the manufacturing resources, key components and products can be sensed and captured.

The first thing that must be done in MMP is setting default data (including product ID and some logical rules to identify the status of products and manufacturing resources) to PEIDs of key components and resources. For example, during the manufacturing stage, when a pallet comes to the machine, this event can be tracked by the UHF RFID reader installed on the machine. Next, UHF RFID reader checks the material need according to this process task. If the materials are well prepared, the processing task can be executed on this machine. Therefore, the real-time data of components and manufacturing resources can be captured. This data is stored in a repository so that the real-time monitoring of WIP and manufacturing resources can be achieved. The assembly plant is not included for discussion here as the working principles are basically similar.

OM process is the phase where compressors are rented and leased to customers. As previously mentioned, compressors are strictly forbidden to work in the surge area. Flow data is one of the key data to prevent the surge of compressors. In addition, the vibration of the rotors and temperature of the compressed gas are also important symbols for surge phenomena. Therefore, the surge phenomenon can be effectively prevented by real-time monitor and analysis of the operation status data (such as flow rate, pressure, temperature, and vibration) of the compressors. In OM stage, although the compressors are away from the company and delivered to customers, the PEIDs (such as smart sensors) that have been deployed (during the manufacturing and assembling process) in key parts and proper location of compressors can be used to monitor and collect operation status data of the compressors in real time. Based on the analysis of field OM data of compressors, the predictive maintenance and other lifecycle decisions (e.g. operation improvement, technology 
improvement, updating product design, optimization production plan, and reuse and remanufacturing) can be executed.

\subsection{MMP big data management and analysis}

Based on the configuration of PEIDs, the big data of compressors MMP can be obtained and transmitted to enterprise database through the defined data relation, data integration rules and middleware technologies (as mentioned in Section 4.1). The big data management and analysis procedures (on the right-hand side of Fig. 6) are depicted as follows.

- Data transmission: including real-time and non-real-time data transmission. For real-time data (e.g. temperature, vibration, pressure and flow rate) transmission, the internet, wireless, and 4G are used, while tools like Sqoop (http://sqoop.apache.org/) are adopted to transmit the non-real-time data (e.g. maintenance history and failure record).

- Data interface: collecting multi-source heterogeneous big data by using different data interface, including design data interface, production data interface and OM data interface, etc.

- Data processing: Storm and Hadoop computing framework are used to process the real-time and non-real-time big data of compressors MMP, respectively.

- Data storage: Distributed approach is used to manage and store the big data of compressor MMP. For example, DDBS should be used to store the structured big data, and HDFS or NoSQL are used to store unstructured big data. XML is a general standard of expressing and exchanging for structured and semi-structured big data. So XML can be used to describe semi-structured big data of MMP. Finally, the semi-structured big data of compressor MMP is unified into a standardized data format and stored in DDBS.

Through establishing the data mining models and applying the big data analytics theories, the knowledge and rules for the optimization of MMP are acquired. By combining the knowledge with PDKM or DSS, the application demands (including project management, fault diagnosis and prediction, service improvement and dynamic workshop scheduling) of the enterprise can be achieved. At the same time, the association rules and association relationships that related to energy consumption and environmental factor can be used to optimize production, improve technology, improve design, evaluate and select more environmentally raw material and cleaner energy.

\subsection{MMP data mining results integrated application}

The big data mining results are not only useful for an individual stage of compressor MMP but also useful for all stages of the whole compressor lifecycle. For example, design departments need to draw lessons from the evaluation result of selection of material, to select cleaner and environmentally friendly material. Maintenance or service departments need to analyze the quality-related factors of production stage to provide better sale service and maintenance 
service. Data mining results of marketing and customers demand can be used by R\&D departments to develop new products. Easily damaged parts with supplier selection evaluation data mining results of service departments can be used by $R \& D$ departments to select better suppliers and improve designs. The mining results of the forecast of orders from service departments can be used by production departments to formulate production plan and reconfigure the production system. Data mining results of MMP can be used by recycling departments and can greatly enhance the effectiveness on EOL management. For example, materials recycle and reuse can be significantly improved because enterprise can obtain accurate knowledge about 'valuable parts and materials': what materials they contain, how long is the residual life of the parts, and other knowledge that will facilitate material reuse (Jun et al., 2009).

\section{Analysis and discussions}

The purposes of the statistical analysis are to evaluate and verify the practicality and feasibility of the proposed service-driven and big data-based business mode. These data contributing to our statistical analysis are enterprise annual reports (http://gg.cfi.cn/cbgg/10909/601369.html), the statistics yearbook of air blower industry of China

(http://www.yearbookinfo.net/), specialized journals, newspapers and market research report (http://www.chinabgao.com/k/fengjizhizao.html).

\subsection{Statistical analyses and discussions}

Three major businesses of company $\mathrm{X}$ are energy conversion device manufacturing (ECDM), energy conversion system service (ECSS) and energy infrastructure operation (EIO). As mentioned at the beginning of Section 5, apart from the provision of pure products to its customers, based on the field big data analysis, company $\mathrm{X}$ is able to provide its customers with application-oriented service. As a result, the company has achieved substantial success.

With the adoption of the innovative service-driven and big data-based business mode, Company X is possible to reveal unexpected insights and able to provide its customers with customized products, specialized maintenance and refurbishment service, remote online diagnoses service, key spare parts, complete solutions, etc. From 2009 to 2012 , the changes in above-mentioned business processes have been translated into a sustainable CNY 0.19 billion to CNY 0.23 billion (http://gg.cfi.cn/cbgg/10909/601369.html) annual profit impact for Company X.

Therefore, an innovative business pattern may bring additional income and profit for traditional manufacturing enterprise. For example, the service-driven mode can effectively reduce the potential risks for customers of purchasing a product. With the development of service-oriented manufacturing, customers usually pay more attention on the function or service provided by the products instead of products themselves. Besides, manufacturer can provide its customers with more endurable and customized products after the proper analysis of the MMP big data. For another example, with the 
adoption of the service-driven and big data-based manufacturing mode, manufacturer can now provide specialized maintenance and refurbishment service to customers proactively, which will increase the lifetime of the product, and reduce the amount of the product in circulation.

By these two patterns, firstly, the satisfaction and loyalty of customers can be greatly increased, more potential customers may be identified, and the product will be more competitive in the market, so as to create more profit for the manufacturing enterprise. Secondly, a new profit growth means could be created by manufacturer through the provision of value-added service business, due to services can extend the value chain of pure product. Thus, this means has further resulted in the transformation from earn-by-product to earn-by-service in manufacturer. Thirdly, the material and energy consumption can be greatly reduced, which reduce the costs and increase the profits of manufacturer.

The validation of the proposed architecture is performed with extensive statistical analysis of the financial data of Company X on operating revenue, profits, and orders trend, respectively. They are analyzed and discussed in detail in the following content of the paper.

As seen in Fig. 7(a), from 2010 to 2013, its annual turnover increases from CNY4.35 billion to CNY6.29 billion with an annual profit increase rate of 20\% during 2010 to 2012. However, comparing with 2013, the overall operating revenue and profits of 2014 fall by $22.7 \%$ and $42.13 \%$ respectively. This is mainly caused by the slowdown of macroeconomic demands, downstream industries cyclical fluctuations and fixed asset investment growth slowed, etc. In addition, the company continuously comes into the new domain in the process of industry transformation and upgrading, which make some changes in the revenue structure of the company, and the overall profits are affected. Several findings obtained from annual reports of the enterprise are discussed as follows:

- Based on big data analytics, the reasonable time for maintenance and repair is achieved. Therefore, company X can provide spare devices to its customers. By this means, the system downtime events that caused by single device failure can be effectively minimized. The losses due to stop of production are reduced and the empty load energy consumption due to the restart of the equipment is also decreased. As shown in Fig. 7 (a), from 2010 to 2013, the operating revenue from the business of ECDM comes to CNY 5.05 billion.

- Based on big data analysis of OM process, company $\mathrm{X}$ is able to provide its customers with specialized maintenance and refurbishing service, which extends the lifespan of products, and increases the recycle rate and reuse rate of products. For CP, it is important to minimize waste and resources consumption. In 2014, orders of maintenance service and new energy are CNY 2.09 billion which accounts for 32\% of the total orders.

- Based on remote online diagnostics and big data analytics, company $\mathrm{X}$ is able to provide its customers with a complete set of system solutions (e.g. system design and PLM). The R\&D and production departments can get 
feedback from the knowledge of OM process to provide better support on decision-making of updating product design, and coordination and optimization on the whole PLM. All of these improvements will benefit CP from the perspective of optimizing the whole lifecycle management. From 2010 to 2013, with providing the whole set system service (e.g. ECSS), the revenue has increased 2.31 folds and 1.53 folds in profit (seen Fig. 7 (a)).

- From 2010 to 2014, despite the overall key technical staff has no obvious difference, the internal structure of enterprise employees have changed obviously. The technical service staff and sale staff have increased to 701 and 161 respectively, and the production staff have decreased from 1422 to 1207 (seen Fig. 7 (b)). This shows that, with the company transforming its business patterns, there will be an increasing need for the supply of services and service-type staff, such as technical support, sales, maintenance, recycling and remanufacturing service, etc.

- By big data analytics, the strategic cooperation among Company X, spare part suppliers and raw material suppliers are set up. Therefore, company $\mathrm{X}$ is able to share production plans and to implement vendor managed inventory (Gao et al., 2009). Through this strategic cooperation, the cost and resources waste of the company can be reduced. The production plan is adjusted according to market demands and the excess production capacity can be avoided. Meanwhile, the material and energy consumption have decreased and the pressure on environmental pollution and energy shortage have also been reduced.

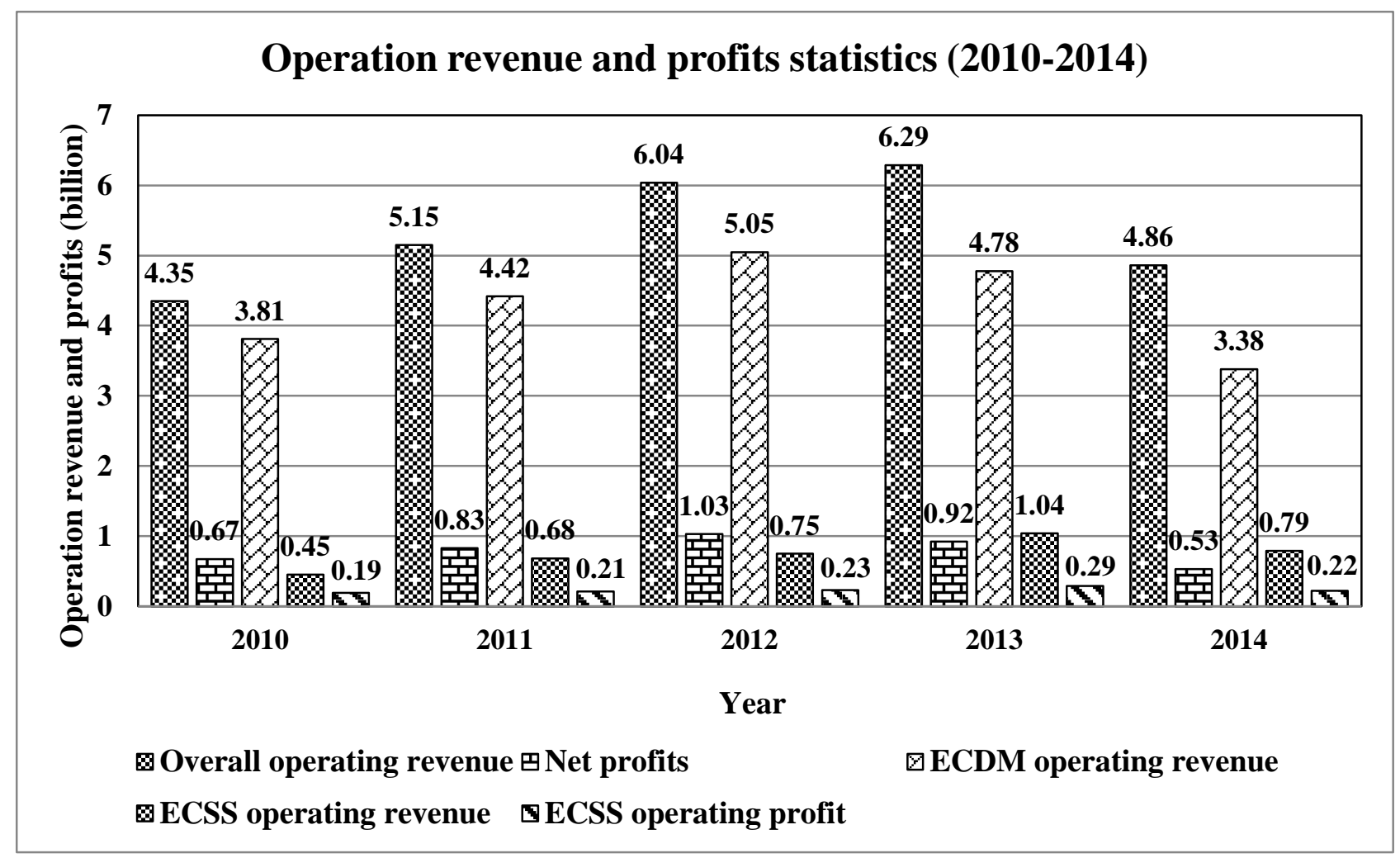

(a) 


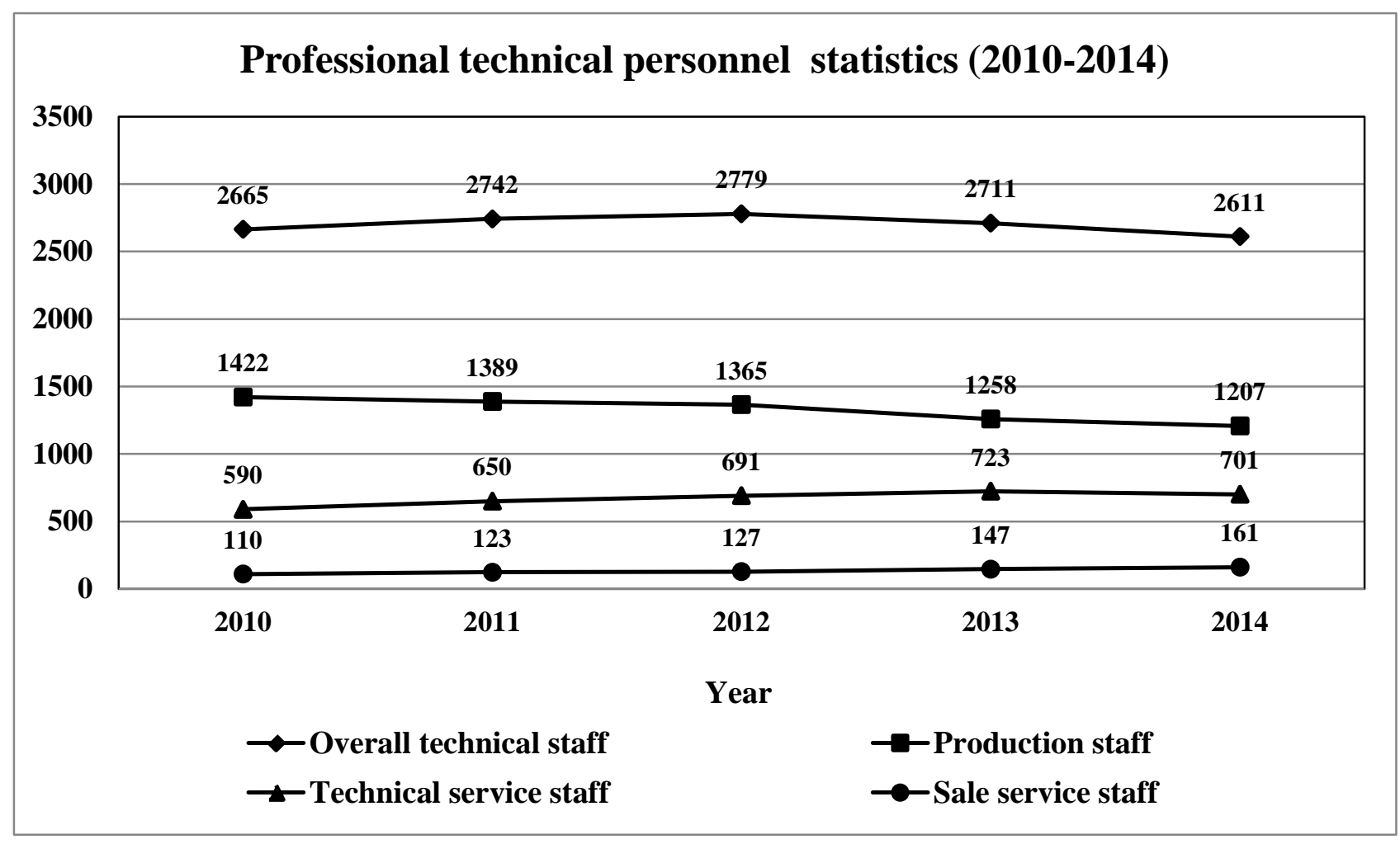

(b)

Fig. 7. Statistical analysis of operating revenue, profits and staff alteration. (a) operating revenue and profits analysis; (b) professional technical personnel alteration analysis.

Along with the transformation of business mode and profit mode, the trend of major businesses orders for company X has changed extremely. Fig. 8 illustrates the change and trend of major businesses orders for company X. The main reasons of these changes are analyzed and listed as follows:

- In 2014, the total orders of three major businesses were CNY 6.56 billion, in which ECSS and EIO orders accounted for 56.49\%. However, the orders of ECDM fell from $79.78 \%$ to $43.54 \%$, decreased by $36.24 \%$. There are two main reasons: (1) macroeconomic situation declined and fixed asset investment growth slowed; (2) with the big data-based and service-driven patterns, the mean time between failures of product was increased and the scrap rate of equipment was reduced. The orders of the ECDM were declined year by year due to the demand of pure products are decreased.

- The orders of EIO have increased significantly (from $0.12 \%$ to $14.24 \%$ ) since company X carried out the new business mode in 2010. As the pressure on environmental protection and energy consumption, company $\mathrm{X}$ is committed to the development of energy conservation and environmental protection industries. It has a higher incentive to design for environment, and resource recycling and utilizing in mind to add value by marketing environmentally friendly and green products. 
- From 2010 to 2014, the orders of ECSS were increased from 20.09\% to 42.25\%. Some reasons are investigated and elaborated before. For example, provision of professional maintenance service, product upgrading service, spare parts service and whole set of system solution were carried out. Beyond that, company X is also able to provide installation and debugging, recycling and remanufacturing, analysis of energy efficiency, energy conservation, and environmental protection engineering design and technical consultation service, etc.

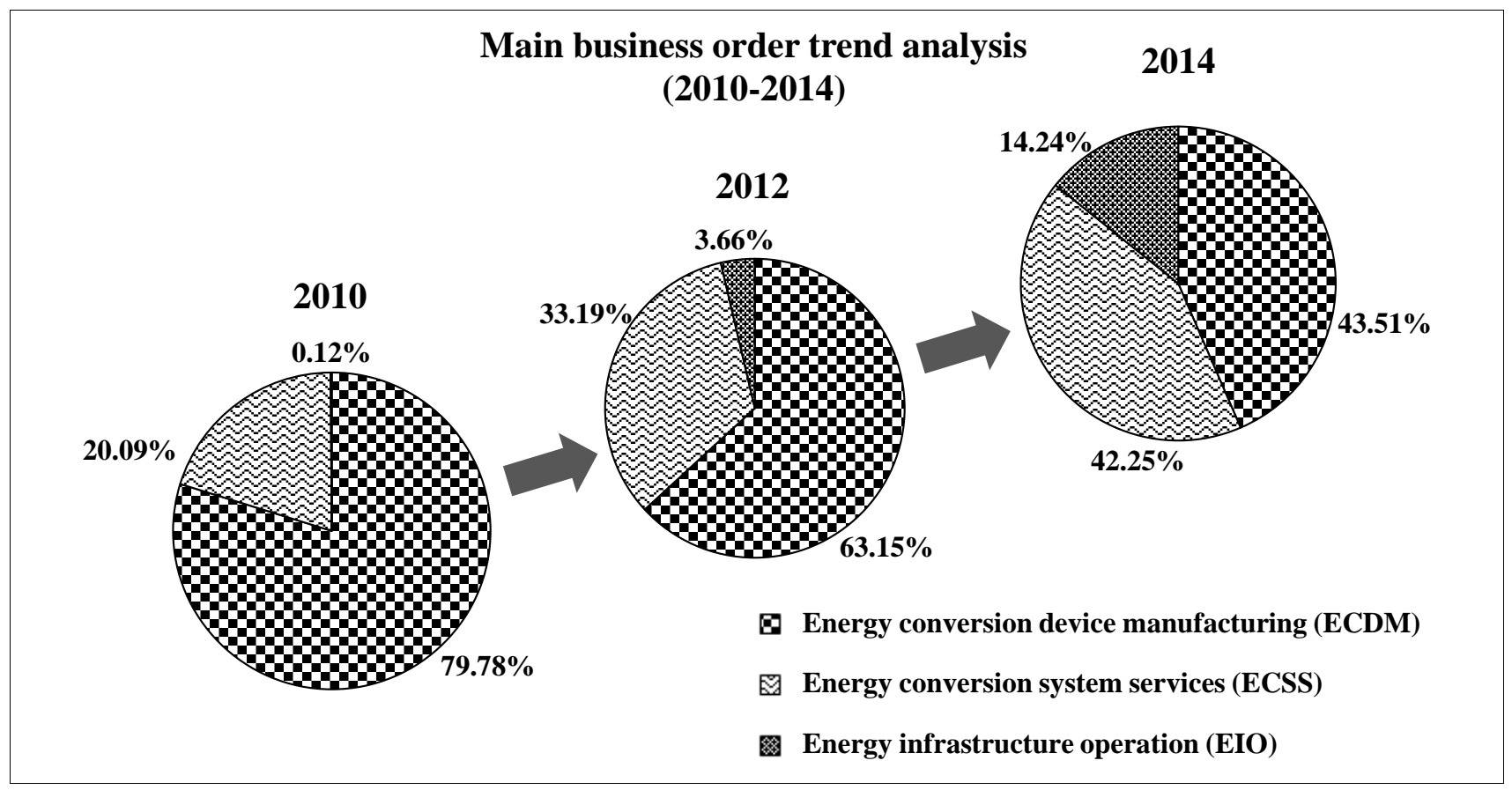

Fig. 8. The orders trend analysis of the three major businesses for company $\mathrm{X}$

By taking advantage of big data-based and service-driven manufacturing pattern, the sales mode of Company X has been transformed from product selling to function or service selling, which has brought more profit for the company. The sales revenue and profits statistics of four major air blower enterprises in China are shown in Table 2. Some observations are as follows:

- From 2009 to 2013, with the rapid development of downstream industries, the demand for air blower product was increasing year by year. The sales revenue and profits maintained stable growth (CNY 12.743 million vs CNY 19.268 million and CNY 0.837 million vs CNY 1.564 million);

- In the past 5 years, the sales revenue of company A was higher than company X (3.609 vs 7.216, 4.35 vs 8.822, 5.151 vs 10.289 , 6.042 vs $10.215,6.289$ vs 10.448$)$. However, the profits of company X were more than two times higher than company A ( 0.538 vs $0.18,0.767$ vs $0.35,0.96$ vs $0.481,1.148$ vs $0.465,1.061$ vs 0.455$)$. This reflected that big data-based and service-driven patterns bring more benefits for company X; 
- The profits of company $\mathrm{X}$ were not only from the sale of physical products but also from products integrated with services. The big data-based product services ensure company X can get higher profits even if it has fewer sales revenue of pure product;

- The main products of company X occupied a higher market share (more than $94 \%$ in the domestic market) with its advanced technology and service which enhance the sustainable competitive advantage to company X.

Table 2

Major air blower enterprises sales revenue and profits (million)

\begin{tabular}{|c|c|c|c|c|c|c|c|c|c|c|}
\hline Name & 2009 & & 2010 & & 2011 & & 2012 & & 2013 & \\
\hline $\begin{array}{l}\text { of } \\
\text { enterprise }\end{array}$ & $\begin{array}{l}\text { Sales } \\
\text { revenue }\end{array}$ & Profits & $\begin{array}{l}\text { Sales } \\
\text { revenue }\end{array}$ & Profits & $\begin{array}{l}\text { Sales } \\
\text { revenue }\end{array}$ & Profits & $\begin{array}{l}\text { Sales } \\
\text { revenue }\end{array}$ & Profits & $\begin{array}{l}\text { Sales } \\
\text { revenue }\end{array}$ & Profits \\
\hline $\mathrm{X}$ & 3.609 & 0.538 & 4.350 & 0.767 & 5.151 & 0.960 & 6.042 & 1.148 & 6.289 & 1.061 \\
\hline A & 7.216 & 0.180 & 8.822 & 0.35 & 10.289 & 0.481 & 10.215 & 0.465 & 10.448 & 0.455 \\
\hline B & 1.191 & 0.100 & 1.231 & 0.072 & 1.247 & 0.068 & 1.476 & 0.046 & 1.707 & 0.034 \\
\hline C & 0.727 & 0.019 & 0.740 & 0.023 & 0.864 & 0.025 & 0.823 & 0.016 & 0.924 & 0.014 \\
\hline
\end{tabular}

Source from http://gg.cfi.cn/cbgg/10909/601369.html, http://www.chinabgao.com/k/fengjizhizao.html

\subsection{Benefits}

Manufacturing enterprises have been able to reduce energy consumption and to avoid uncertainties in their manufacturing processes, and dramatically improve their quality of products and services by adopting advanced production management paradigms (e.g. lean production and Six Sigma programs) (Auschitzky et al., 2014). However, in some manufacturing environments in which process complexity and process uncertainty are present (e.g. MMP of large equipment and complex product), the internal and hidden interdependencies among the different stages or parameters are difficult to discover, sometimes even after advanced production management paradigms have been applied.

Given the complexity of MMP for complex product that influences the efficiency of successfully implementing and maintaining a CP strategy, original equipment manufacturers (OEMs) need a new systematic and integrated method to diagnose, correct and optimize the MMP flaws. Big data analytics based on the MMP data proposed in this paper provides such an approach.

Big data analytics refers to the application of statistics and other mathematical tools to MMP data in order to optimize production process and technological parameter, reduce resources consumption and improve service quality. During MMP of complex products, enterprise managers can use big data analytics to make a deep analysis on the historical and real-time MMP data, identify hidden relationships among different stages and parameters, and then optimize the factors that are proven to have the greatest effect on the CP and PLM. In addition, big data analytics can be a critical tool to realize the optimization of lifecycle decision-making. The processes include gathering historical isolated data sets 
actively, aggregating them, and analyzing them to reveal invaluable new insights. Therefore, manufacturing enterprises taking advantage of big data analytics can reduce manufacturing defect and energy consumption, save time and money.

Key problems for many customers or small and medium-sized enterprises (SMEs) to adopt big data analytics-enabled manufacturing solutions are the high cost, high risk and high level of technical skills (Huang et al.,2012). However, sharing and leasing pattern mentioned in the above application scenario can overcome these problems. Big data analytics-enabled and service-driven manufacturing patterns may benefit the customers, manufacturers, and environment.

\section{For customers}

- Frees customers from the complicated OM process of products. The OM management can be solved by OEMs due to the specialized knowledge, skills and rich experiences.

- Exempts customers from the high cost and high risk of purchasing a product.

- OEMs retain the ownership of products, they are motivated to produce more endurable products and responsible for the recovery of the products.

For manufacturers

- By providing proactive service and enhancing customer satisfaction, to foster the loyalty between customers.

- Given the potential for OEMs to improve their SCA by continual product innovation, technology improvement, production optimization and CP strategy.

- Providing the opportunity to OEMs to enhance its ability in perceiving, predicting and inducing market demand.

- Attaching additional value to a product. For example, the knowledge discovered from the MMP big data can be sold as consulting and training services (Mittermeyer et al., 2010).

For environment

- Reusing, refurbishing and recycling the products by specialized service. The use frequency and use intensity of the products are increased.

- Decreasing the total amount of products by designing and producing more endurable and reliable products.

- Fewer products in circulation, reducing material and energy consumption, and less incinerated or landfilled.

\subsection{Managerial implications}

Managerial implications could be generated from hidden knowledge and key findings of big data, which are useful when various department managers are making lifecycle decisions accordingly. Aiming at the MMP of complex products, four managerial implications of the proposed architecture are included, especially for marketing department, R\&D department, production department and service department. 


\section{For marketing department}

To identify who are their promising customers and forecast customers' unspoken needs. When a more precise targeting is put forward, it is advisable to match various products with various customers, respectively. Big data analytics makes it possible to pick the most suited customers from the great amount of customers' data. In addition, as customers' requirements for product have an exponential growth, forecasting customers' unspoken needs is a critical task for the marketing department. The forecasting usually comes from the customers' searching recordings, and historical purchasing behaviors.

\section{For R\&D department}

To present the appropriate solutions in conceptual design stage, make decisions in detailed design stage, and realize product innovative design. Firstly, the design requirements and constraints during the conceptual design stage are always imprecise. As time goes on, historical data of product design become bigger and bigger, big data analytics can be used to analyze these data. Therefore, the hidden schemes to meet the design specification in conceptual design stage could be achieved. Secondly, during detailed design phase, there are countless templates which can be used for reference. The big data analytics here is used to identify the most correlative examples as detailed as possible to give guidance for the new products development. Thirdly, with the help of PEIDs, the data of production, operation, maintenance and recycling can be feedback to R\&D department, as a new requirement of product characteristic and function for product innovative design. For instance, design for reliability, design for disassembly and design for environment.

\section{For production department}

To monitor product quality, manage production equipment and increase equipment energy efficiency. With the help of PEIDs, huge amount of multi-source, heterogeneous and real-time data of production and equipment operation have been generated. Big data analytics can be used to track the product quality and estimate equipment wear due to the extraordinary capabilities to integrate, process, and analyze the dynamic and real-time data. Furthermore, with the help of big data analytics, the optimization of workshop scheduling decisions (e.g. which machine should operate at what speed at what time) could be relatively easy to achieve. The energy efficiency of equipment could be increased.

\section{For service department}

To increase the customers' satisfaction by the innovative service strategies, such as, product quality real-time monitoring service, and predictive maintenance service. In order to select a suitable service or maintenance strategies, it is necessary to monitor product's status continuously, which definitely generates an amazing number of data. Big data analytics should be used to analyze the data. Meanwhile, the PEIDs have made it possible to trace the products through its lifecycle and to feedback the operation status of the products to the OEMs. Thus, big data analytics can provide 
opportunities for predictive maintenance. Through analyzing the historical maintenance record and real time operation data, the maintenance plan will be taken to prevent the failure before it actually occurs.

\section{Conclusions}

To solve the problems of data availability for PLM, Auto-ID and smart sensor technology have been widely used by manufacturing enterprise to monitor and track of their product in real-time. Such an automatic data generation and collection approach brings new challenges, for example, how to sense and exchange the multi-source heterogeneous big data during the whole lifecycle, and how to use the real-time and multi-source lifecycle big data to discover and share the hidden knowledge to improve all stages of PLM and CP. To address these problems, in this research, a new systematic integration solution is proposed to provide a new paradigm for manufacturing enterprises to enhance the efficiency of PLM and CP. The new paradigm can provide a theoretical and practical basis for the sustainable development of other manufacturing enterprises.

This research brings four contributions to successfully implement and maintain CP strategy. The first contribution is the architecture of BDA-PL and its key components. Under the new big data based lifecycle management patterns, manufacturers can use advanced analytics tool to take a deep dive into real-time and historical MMP data, identify interrelationship among different lifecycle stages, reveal important insights, and then optimize the factors that are prove to have the greatest effect on the CP. The second contribution is the framework of big data capturing and integration for MMP based on IoT. It can be used to the active perception and collection of the real-time and multi-source MMP big data of the products, and then process and exchange the real-time big data between heterogeneous enterprise information systems. The third contribution is the graphical model of MMP big data mining and the knowledge sharing mechanism of MMP. Effective data mining not only requires a clear understanding of the application demands involved but also needs an inordinate amount of data preparation (identifying important variables, extracting suitable data) and accurate prediction or classification model. Without proper data preparation and accurate model, data mining is apt to generate useless information. The fourth contribution is a novel concept of integrating big data analytics with product service, which is illustrated in the application scenario. Considering the SCA of sustainable production and cleaner production, a product consumption pattern of leasing is analyzed for future reducing energy consumption and environment pollution.

The validation and justification of the proposed big data analytics architecture are discussed in details through the case company. Using the proposed architecture, revenues and profits of the case company were not only from sale of the physical products but also from products integrated with services. The proposed architecture can benefit the customers, manufacturers, and environment. In addition, managerial implications obtained from the proposed architecture benefit 
four departments (marketing department, R\&D department, production department and service department). Then the four departments are able to make efficient and precise decisions during different lifecycle stages and in different situations, as well as effectively promote the implementation of CP.

The proposed architecture and key enabling technologies of BDA-PL just provide a new kind of useful infrastructure and overall framework to improve the efficiency of PLM and CP by using the MMP big data. Future research works will be carried out on the following aspects. Firstly, how to use the advanced big data analytics tool to work out a mathematical model and to discover the hidden knowledge or rules from the MMP big data for optimizing the lifecycle management and CP process decision. Secondly, in order to provide comprehensive and reliable knowledge to manufacturers, how to realize the integration of the big data mining results and integration mining of big data need to be taken into account. Thirdly, in order to convert the results of big data analytics into easy comprehensible forms, the representation and visualization of excavated knowledge will be studied given different applications and different management departments.

\section{Acknowledgement}

The authors would like to acknowledge financial supports of National Science Foundation of China (51175435), the 111 Project Grant (B13044), and the Yunnan Applied Basic Research Projects (2013FD049).

\section{References}

[1]. Auschitzky, E., Hammer, M., Rajagopaul, A., 2014. How big data can improve manufacturing. McKinsey Glob. Inst. Available at: http://www.mckinsey.com/insights/operations/how_big_data_can_improve_manufacturing (accessed 25.05. 2015).

[2]. Ball, P.D., Evans, S., Levers, A., Ellison, D., 2009. Zero carbon manufacturing facility -towards integrating material, energy, and waste processflows. Proc. Inst. Mech. Eng. Part B: J. Eng. Manuf. 223 (9), 1085-1096.

[3]. Bennane, A., Yacout, S., 2012. LAD-CBM; new data processing tool for diagnosis and prognosis in condition-based maintenance. J. Intell. Manuf. 23(2), 265-275.

[4]. Beuren, F. H., Ferreira, M. G. G., Miguel, P. A. C. 2013. Product-service systems: a literature review on integrated products and services. J. Clean. Prod. 47, 222-231.

[5]. Callia, R.C., Guerrini, F.M., de Castro, M., 2009. The impact of Six Sigma in the performance of a pollution prevention program. J. Clean. Prod.17 (15),1303-1310

[6]. Chen, Y. S., Cheng, C. H., Lai, C. J., 2012. Extracting performance rules of suppliers in the manufacturing industry: An empirical study. J. Intell. Manuf. 23(5), 2037-2045. 
[7]. Cheung, W.M., Marsh, R., Griffin, P.W., Newnes, L.B., Mileham, A.R., Lanham, J.D., 2015. Towards cleaner production: a roadmap for predicting product end-of-life costs at early design concept. J. Clean. Prod. 87, $431-441$.

[8]. Chien, C. F., Chang, K. H., Wang, W. C., 2013. An empirical study of design-of-experiment data mining for yield-loss diagnosis for semiconductor manufacturing. J. Intell. Manuf. 1-12.

[9]. Choudhary, A. K., Harding, J. A., Tiwari, M. K., 2009. Data mining in manufacturing: a review based on the kind of knowledge. J. Intell. Manuf. 20(5), 501-521.

[10]. Corominas, L., Larsen, H.F., Flores-Alsina, X., Vanrolleghem, P.A., 2013. Including life cycle assessment for decision-making in controlling wastewater nutrient removal systems. J. Environ. Manag. 128, 759-67.

[11]. Dai, J.Q., Huang, J., Huang, S.S., Huang, B., Liu, Y., 2011. Hitune: data flow-based performance analysis for big data cloud. In: Proceeding of the 2011 USENIXAnnual Technical Conference, 87-100.

[12]. Galletti, A., Papadimitriou, D.C., 2013. How big data analytics are perceived as a driver for competitive advantage: a qualitative study on food retailers. Master thesis, 1-58.

[13]. Gao, J., Yao, Y., Zhu, V.C.Y., Sun, L., Lin, L., 2009. Service-oriented manufacturing: a new product pattern and manufacturing paradigm. J. Intell. Manuf. 22 (3), 435-446.

[14]. Geng, X., Chu, X., Zhang, Z., 2012. An association rule mining and maintaining approach in dynamic database for aiding product-service system conceptual design. Int. J. Adv. Manuf. Tech. 62(1-4), 1-13.

[15]. Georgiadis, P., Athanasiou, E., 2010. The impact of two-product joint lifecycles on capacity planning of remanufacturing networks. Eur. J. Oper. Res. 202(2), 420-433.

[16]. Giannetti, B.F., Bonilla, S.H., Silva, I.R., Almeida, C.M.V.B., 2008. Cleaner production practices in a medium size gold-plated jewelry company in Brazil: when little changes make the difference. J. Clean. Prod. 16, 1106-1117.

[17]. Grüninger, M., Shapiro, S., Fox, M.S., Weppner, H., 2010. Combining RFID with ontologies to create smart objects. Int. J. Prod. Res. 48(9), 2633-2654.

[18]. Hadaya, P., Marchildon, P., 2012. Understanding product lifecycle management and supporting systems. Ind. Manage. Data. Syst. 112(4), 559-583.

[19]. Huang, G. Q., Qu, T., Zhang, Y., Yang, H. D., 2012. RFID-enabled product-service system for automotive part and accessory manufacturing alliances. Int. J. Prod. Res. 50(14), 3821-3840.

[20]. Huang, Y., Luo, J., Xia, B., 2013. Application of cleaner production as an important sustainable strategy in the ceramic tile plant e a case study in Guangzhou, China. J. Clean. Prod. 43, 113-121.

[21]. Jeong, S., Shimoyama, K., 2011. Review of data mining for multi-disciplinary design optimization. Proc. Inst. Mech. Eng. G: J. Aerospace Eng. 225(5), 469-479. 
[22]. Jun, H. B., Shin, J. H., Kim, Y. S., Kiritsis, D., Xirouchakis, P., 2009. A framework for RFID applications in product lifecycle management.Int. J. Comp. Integ. M. 22(7), 595-615.

[23]. Jun, H. B., Shin, J. H., Kiritsis, D., Xirouchakis, P., 2007. System architecture for closed-loop PLM. Int. J. Comp. Integ. M. 20(7), 684-698.

[24]. Kantola, J., et al., Call for papers for a Special Volume of the Journal of Cleaner Production on "Innovative Products and Services for Sustainable Societal Development”, J. Clean. Prod.(2015), http://dx.doi.org/10.1016/j.jclepro.2015.01.067

[25]. Kiritsis, D., Bufardi, A., Xirouchakis, P., 2003. Research issues on product lifecycle management and information tracking using smart embedded systems. Adv. Eng. Inform. 17(3), 189-202.

[26]. Köksal, G., Batmaz, İ., Testik, M. C., 2011. A review of data mining applications for quality improvement in manufacturing industry. Expert. Syst. Appl. 38(10), 13448-13467.

[27].Kupusovic, T., Midzic, S., Silajdzic, I., Bjelavac, J., 2005. Cleaner production measures in small-scale slaughterhouse industry e case study in Bosnia and Herzegovina. J. Clean. Prod. 15, 378-383.

[28]. Laney, D., 2001. 3D data management: controlling data volume, velocity and variety. META Group Research Note. Available http://blogs.gartner.com/doug-laney/files/2012/01/ad949-3D-DataManagement-Controlling-Data-Volume-Velocityand-Variety.pdf

[29]. Lee, B. E., Suh, S. H., 2009. An architecture for ubiquitous product life cycle support system and its extension to machine tools with product data model. Int. J. Adv. Manuf. Tech. 42(5-6), 606-620.

[30]. Lee, C.K.H., Ho, G.T.S., Choy, K.L., Pang, G.K.H., 2014. A RFID-based recursive process mining system for quality assurance in the garment industry. Int. J. Prod. Res. 52 (14): 4216-4238.

[31]. Li, J.R., Tao, F., Cheng, Y., Zhao, L.J., 2015. Big Data in product lifecycle management. Int. J. Adv. Manuf. Tech. 84(1-4), 667-684

[32]. Liu, Y., 2013. Sustainable competitive advantage in turbulent business environments. Int. J. Prod. Res. 51(10), 2821-2841.

[33]. Liu, Y., Liang, L., 2015. Evaluating and developing resource-based operations strategy for competitive advantage: a n exploratory study of Finnish high-tech manufacturing industries. Int. J. Prod. Res. 53(4), 1019-1037.

[34]. Luken, R., Rompaey, F.V., 2008. Drivers for and barriers to environmentally sound technology adoption by manufacturing plants in nine developing countries. J. Clean. Prod. 16 (1 Suppl. 1), S67-S77.

[35]. Magro, M. C., Pinceti, P., 2009. A confirmation technique for predictive maintenance using the Rough Set 
Theory. Comput. Ind. Eng. 56(4), 1319-1327.

[36]. Mavridou, E., Kehagias, D. D., Tzovaras, D., Hassapis, G., 2013. Mining affective needs of automotive industry customers for building a mass-customization recommender system. J. Intell. Manuf. 24(2), 251-265.

[37]. Metan, G., Sabuncuoglu, I., Pierreval, H., 2010. Real time Selection of Scheduling Rules and Knowledge Extraction Via Dynamically Controlled Data Mining. Int. J. Prod. Res. 48(23): 6909-6938.

[38]. Mittermeyer, S.A., Njuguna, J.A., Alcock, J.R., 2010. Product-service systems in health care: case study of a drug-device combination. Int. J. Adv. Manuf. Tech. 52 (9-12), 1209-1221.

[39]. Murillo-Luna, J.L., Garces-Ayerbe, C., Rivera-Torres, P., 2011. Barriers to the adoption of proactive environmental strategies. J. Clean. Prod. 19 (13), 1417-1425.

[40]. Ngai, E. W., Xiu, L., Chau, D. C., 2009. Application of data mining techniques in customer relationship management: A literature review and classification. Expert. Syst. Appl. 36(2), 2592-2602.

[41]. Osman, M. S., Ram, B., Stanfield, P., Samanlioglu, F., Davis, L., Bhadury, J., 2010. Radio frequency identification system optimisation models for lifecycle of a durable product. Int. J. Prod. Res. 48(9), 2699-2721.

[42]. Purarjomandlangrudi, A., Ghapanchi, A. H., Esmalifalak, M., 2014. A data mining approach for fault diagnosis: An application of anomaly detection algorithm. Measurement. 55(1), 343-352.

[43]. Rabl, T., Gómez-Villamor, S., Sadoghi, M., Muntés-Mulero, V., Jacobsen, H.-A.,Mankovskii, S., 2012. Solving big data challenges for enterprise applicationperformance management. Proc. VLDB Endow. 5 (12), 1724-1735.

[44].Sallez, Y., Berger, T., Deneux, D., Trentesaux, D., 2010. The lifecycle of active and intelligent products: The augmentation concept. Int. J. Comp. Integ. M. 23(10), 905-924.

[45]. Silva, D.A., Delai, I., Castro, M.A., Ometto, A.R., 2013. Quality Tools Applied to Cleaner Production Programs: A First Approach Towards a New Methodology. J. Clean. Prod. 47, 174-187.

[46]. UNEP DTIE (United Nations Environmental Programme-Division of Technology, Industry and Environment), 1996. Cleaner Production-a Resource Training Package, first ed. United Nations Publication, Paris.

[47]. UNIDO (United Nations industrial development organization), 2002. Manual on the Development of Cleaner Production Policies-Approaches and Instruments. Guidelines for National Cleaner Production Centres and Programmes.http://www.unido.org/fileadmin/import/9750_0256406e.pdf (accessed 02.06.15.).

[48]. USEPA (United States Environmental Protection Agency), 1998. Principles of Pollution Prevention and Cleaner Production: an International Training Course (Participant’s Manual). http://www.p2pays.org/ref/02/01993.pdf (accessed 02.06.15.).

[49]. Vinodh, S., Prakash, N.H., Selvan, K.E., 2011. Evaluation of agility in supply chains using fuzzy association rules 
mining. Int. J. Prod. Res. 49(22): 6651-6661.

[50]. Wang, H. W., Chen, S., Xie, Y., 2010. An RFID-based digital ware-house management system in the tobacco industry: A case study. Int. J. Prod. Res. 48(9), 2513-2548.

[51]. Wei, F. F., 2013. ECL Hadoop: “Big Data” processing based on Hadoop strategy in effective e-commerce logistics. Comput Eng Sci 35(10):65-71.

[52]. White, T., 2012. “MapReduce and the hadoop distributed file system”, in Hadoop: The definitive guide, 1st edition, O'Reilly Media, Inc., Yahoo press.

[53]. Xu, D. F., Li, Q., Jun, H. B., Browne, J., Chen, Y. L., Kiritsis, D., 2009. Modelling for product information tracking and feedback via wireless technology in closed-loop supply chains. Int. J. Comp. Integ. M. 22(7), 648-670.

[54]. Yang, X., Moore, P., Chong, S. K., 2009. Intelligent products: From lifecycle data acquisition to enabling product-related services. Comput. Ind. 60(3), 184-194.

[55]. Zhang, Y.F., Zhang, G., Wang, J.Q., Sun, S.D., Si, S.B., Yang, T., 2015. Real-time information capturing and integration framework of the internet of manufacturing things. Int. J. Comp. Integ. M. 28(8), 811-822.

[56]. Zhang, Y.F., Xu, J.X., Sun, S.D., Yang, T., 2015a.

Real-time information driven intelligent navigation method of assembly station in unpaced lines. Comput.

Ind. Eng. 84, 91-100.

[57]. Zhang, Y.F., Zhang, G., Du, W., Wang, J.Q., Ali, E., Sun, S.D., 2015b. An optimization method for shopfloor materia 1 handling based on real-time and multi-source manufacturing data. Int. J. Prod. Econ. 165, 282-292.

[58]. Zhang, Y.F., Liu, S., Liu, Y., Li, R. 2016. Smart box enabled product-service system for cloud logistics, Int. J. Prod. Res., DOI: 10.1080/00207543.2015.1134840. 